\title{
13. PALEOMAGNETIC STUDIES OF BASALTS AND ANDESITES FROM DEEP SEA DRILLING PROJECT LEG 59
}

\author{
B. Keating and E. Herrero, Hawaii Institute of Geophysics, Honolulu, Hawaii
}

\section{INTRODUCTION}

Paleomagnetic studies were conducted on basalts from two Leg 59 sites, 447 and 448 . Site 447 is situated in the West Philippine Basin, and Site 448 is on the Palau-Kyushu Ridge, which separates the Philippine and Parece Vela Basins. Our sampling and measurement procedures were the same as those used for Leg 59 sediments and described in Chapter 1 of this volume. As in that chapter sample identification consists of hole, core, and section number, followed by depth (in $\mathrm{cm}$ ) within the section.

\section{HOLE 447A}

The basaltic basement in Hole 447A was divided into six petrographic units, the petrology of which can be summarized as follows:

Unit 6-plagioclase phyric tholeiitic basalt

Unit 7-aphyric pillowed tholeiitic basalt

Unit 8-four pillowed massive flow eruptive units

Unit 9-Aphyric dolerite

Unit 10-olivine-plagioclase-clinopyroxene phyric tholeiitic basalt

Unit 11-Olivine-plagioclase phyric tholeiitic basalt Several samples were collected from each unit which were representative of the different rock types. A pilot group of samples was progressively demagnetized in multiple steps up to 1000 Oe (alternating field). On the basis of these results the remainder of the samples were demagnetized at 250 Oe. A stereonet projection of several of the pilot set samples is shown in Figure 1. Most of the samples were stably magnetized and displayed very little change in direction; examples include Samples 447A-14-2, 53, 447A-14-2, 107, 447A-14-3, 29, and 447A-16-1, 11. However, six of the samples from this hole displayed large changes in the direction of magnetization upon demagnetization, which is suggestive of unstable magnetization (see, for example, Samples 447A-16-2, 24, 447A-18-3, 20, and 447A-20-3, 48).

Normalized plots of intensity versus demagnetization field are shown in Figure 2. Four different types of demagnetization curves seem to characterize samples from this hole. Sample 447A-14-2, 107 displays the gradual decay of intensity upon demagnetization most often displayed by DSDP core material. Samples 447A16-1, 11 and 447A-25-2, 76 show an increase in intensity after demagnetization, followed by a progressive decrease, which reflects the removal of a less stable secondary magnetized direction in opposition to the primary direction of magnetization. A third demagnetization
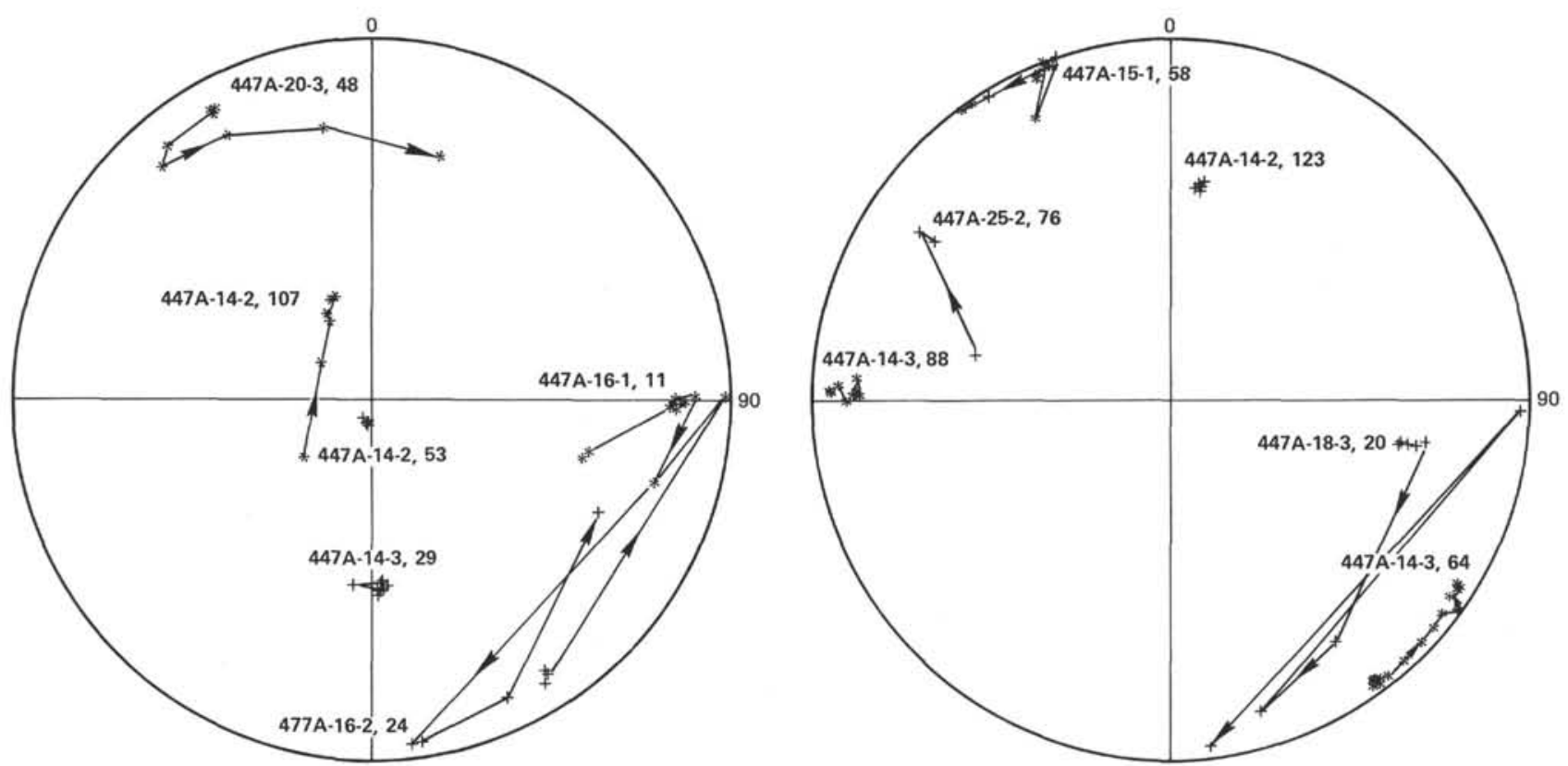

Figure 1. Stereonet projections of changes in magnetic directions with demagnetization for samples from Hole 447A. (Arrows indicate direction of change upon progressive demagnetization, stars $=$ negative inclination, and crosses $=$ positive inclination.) 

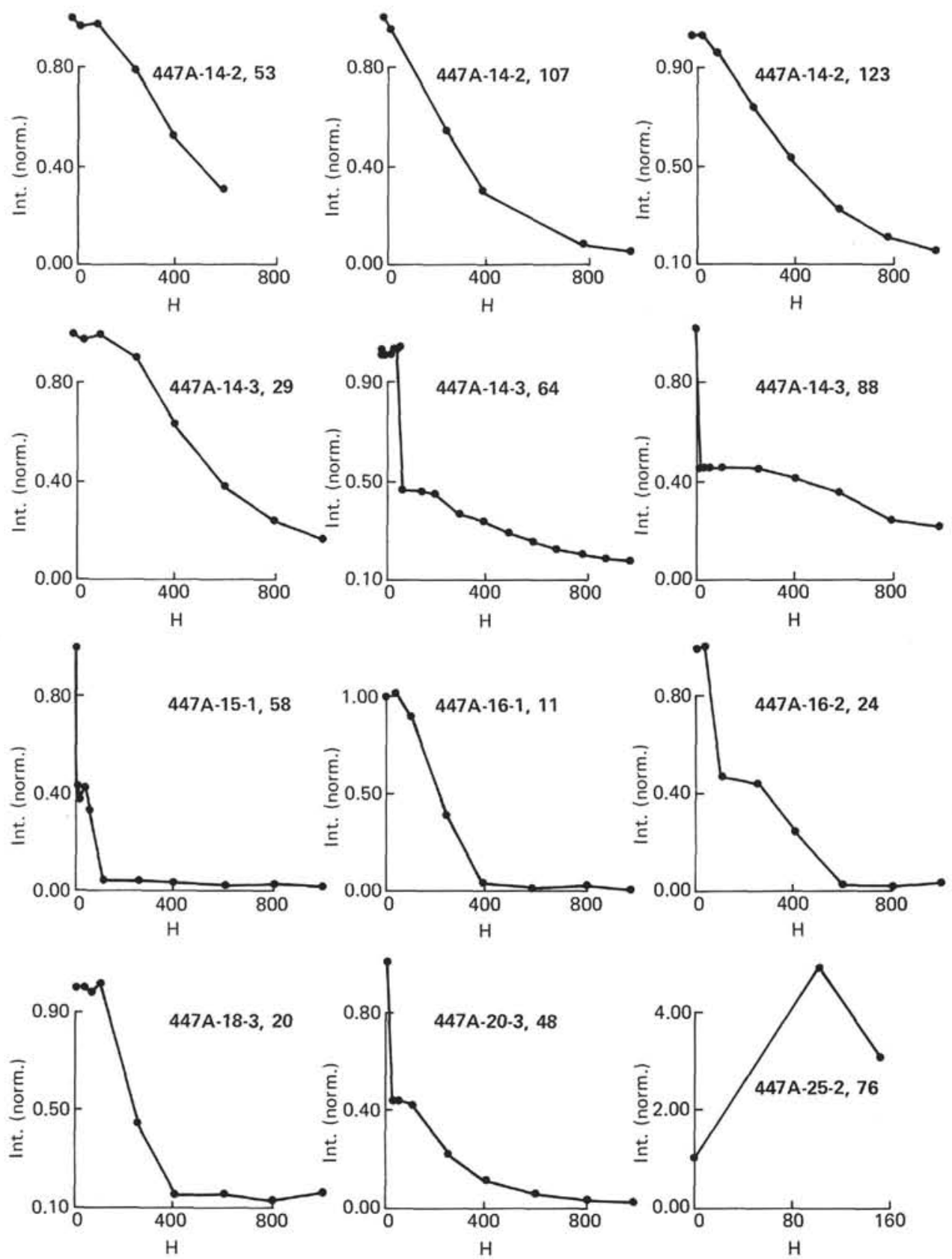

Figure 2. Plots of normalized intensity (vertical axis) versus alternating current demagnetization field (Oe) for samples from Hole 447A.

behavior is exhibited by Samples 447A-14-3, 29, 447A$18-3,20$, and $447 \mathrm{~A}-14-2,53$. In this case, very little change in intensity occurred after the first few steps (up to about $100 \mathrm{Oe}$ ), but then a sharp decrease occurred. The last demagnetization behavior was exemplified in pilot study Samples 447A-16-2, 24, and 447A-20-3, 48. These demagnetization curves suggest that a very low coercivity component of magnetization was the first to be removed at low fields. Progressive and gradual loss of magnetization occurred after removal. The least stable samples display this fourth type of behavior.

Six samples from Site 447 displayed large and erratic change in direction of magnetization upon demagnetiza- tion. After these unstable magnetized samples, 447A14-2, 123, 447A-16-2, 24, 447A-18-3, 20, 447A-20-3, 48, $447 \mathrm{~A}-21-4,110$, and $447 \mathrm{~A}-30-1,53$, were removed from the data set, mean paleolatitudes for the site and for the individual petrographic units were calculated. The results of the calculations are summarized in Table 1. The means were calculated in two ways. The first was based on the absolute values of the sample inclinations (after demagnetization to $250 \mathrm{Oe}$ ). The mean could be representative if the site were situated to either side of the equator and both polarities were present in the data set. The second mean included both the positive and negative inclination data and would be representative if 
Table 1. Paleolatitude summary for Holes $447 \mathrm{~A}$ and 448A.

Hole 447A

Mean paleolatitude (absolute value of inclination) $\quad 6.0$

Standard Deviation 13.

Mean paleolatitude (calculated using both signs) $\quad 6.6$

Standard Deviation

17.2

Hole 448A

Mean paleolatitude (absolute value of inclination) $\quad 7.8$

Standard Deviation

10.0

Mean paleolatitude (calculated using both signs) $\quad 5.7$

Standard Deviation

14.5

\begin{tabular}{clcc}
\hline \multicolumn{5}{c}{ Hole 447A } \\
Rock Unit & \multicolumn{1}{c}{ Rock Type } & $\begin{array}{c}\text { Number of } \\
\text { Samples }\end{array}$ & Paleolatitude \\
\hline 6 & Tholeiitic basalt & 18 & 4.4 \\
7 & Pillow basalt & 3 & 2.2 \\
8 & Pillow basalt & 17 & 3.5 \\
9 & Dolerite & 4 & 8.2 \\
10 & Tholeiitic basalt & 10 & 3.8 \\
11 & Tholeiitic basalt & 12 & 14.5 \\
\hline
\end{tabular}

Hole 448A

\begin{tabular}{clcc} 
Rock Unit & \multicolumn{1}{c}{ Rock Type } & $\begin{array}{c}\text { Number of } \\
\text { Samples }\end{array}$ & Paleolatitude \\
\hline 12 & Flow basalt & 1 & 1.4 \\
13 & Pillow basalt & 2 & 5.0 \\
14 & Pillow basalt & 1 & 3.1 \\
18 & Flow basalt & 1 & 0.3 \\
19 & Volcanic breccia & 2 & 5.6 \\
20 & Flow basalt & 3 & 15.1 \\
21 & Volcanic breccia & 1 & 13.2 \\
22 & Massive flow basalt & 1 & 14.5 \\
23 & Volcanic breccia & 1 & 5.9 \\
24 & Flow basalt & 3 & 4.3 \\
26 & Basalt dike & 1 & 15.2 \\
27 & Basalt dike & 1 & 3.9 \\
29 & Volcanic breccia & 1 & 21.6 \\
31 & Basalt/andesite flow & 1 & 0.4 \\
33 & Basalt flow & 4 & 5.0 \\
34 & Volcanic breccia & 2 & 8.4 \\
35 & Sill & 1 & 4.6 \\
37 & Basalt dike & 3 & 10.2 \\
40 & Volcanic breccia & 2 & 4.7 \\
42 & Tuff-breccia & 2 & 4.0 \\
46 & Tuff & 1 & 7.7 \\
47 & Sill basalt & 2 & 10.2 \\
48 & Volcanic breccia & 1 & 3.5 \\
49 & Andesite dike & 1 & 7.5 \\
51 & Basalt dike & 3 & 16.3 \\
\hline
\end{tabular}

the site were situated near the equator, where the presence of both "normal" and "reversed" polarity could be expected even without a polarity change of the field due to secular variation. It seems less likely that the site was exactly on the equator than near it, since the standard deviation is greater when the mean is calculated for the equatorial case than the nonequatorial case. The opposite would be expected if the site were truly equatorial. Paleolatitudes from both cases were shallow. The paleolatitudes from Units 6 through 10 vary from $2.2^{\circ}$ to $8.2^{\circ}$. The paleolatitudes from Unit 11 appear significantly higher than the remaining units; the mean is $14.5^{\circ}$.

The individual sample inclinations have been plotted stratigraphically in Figure 3 and summarized in Tables 2 and 3. The difference in paleoinclinations for Unit 11 versus Units 6 through 10 is obvious. The inclination data for this site are fairly consistent, except for an occasional single point in a sequence which displays the opposite polarity. These single point reversals very likely represent undetected sample inversions that occurred in the core lab during labeling and description. If we ignore these single point inversions we find a consistent sequence of inclinations down-hole which may be a sequence of magnetic field reversals. The interval from 113 to 115 meters depth was characterized by a sequence of positive to negative to positive inclinations. Samples with negative inclinations occurred from 115 to 151,155 to 180 , and 271 to 273 meters depth, and those with postive inclinations occurred at 152 to 154,187 to 193 , and 187 to 255 meters depth. It was only petrographic Units 7,9 , and 10 that were characterized by inclinations of a single sign.

\section{HOLES 448 AND 448A}

Two holes were drilled at Site 448. Only five samples were collected from the basalts of Hole 448; the remainder of basement samples came from Hole 448A. If any overlap occurs it is with Samples 448-59-2, 89 and 448-61-3, 100 and Samples 448A-15-3, 112, 448A-16-3, $24,448 \mathrm{~A}-17-2,56,448 \mathrm{~A}-18-1,102$, and 448A-20-3, 75 (see site summary for further explanation). We identi-

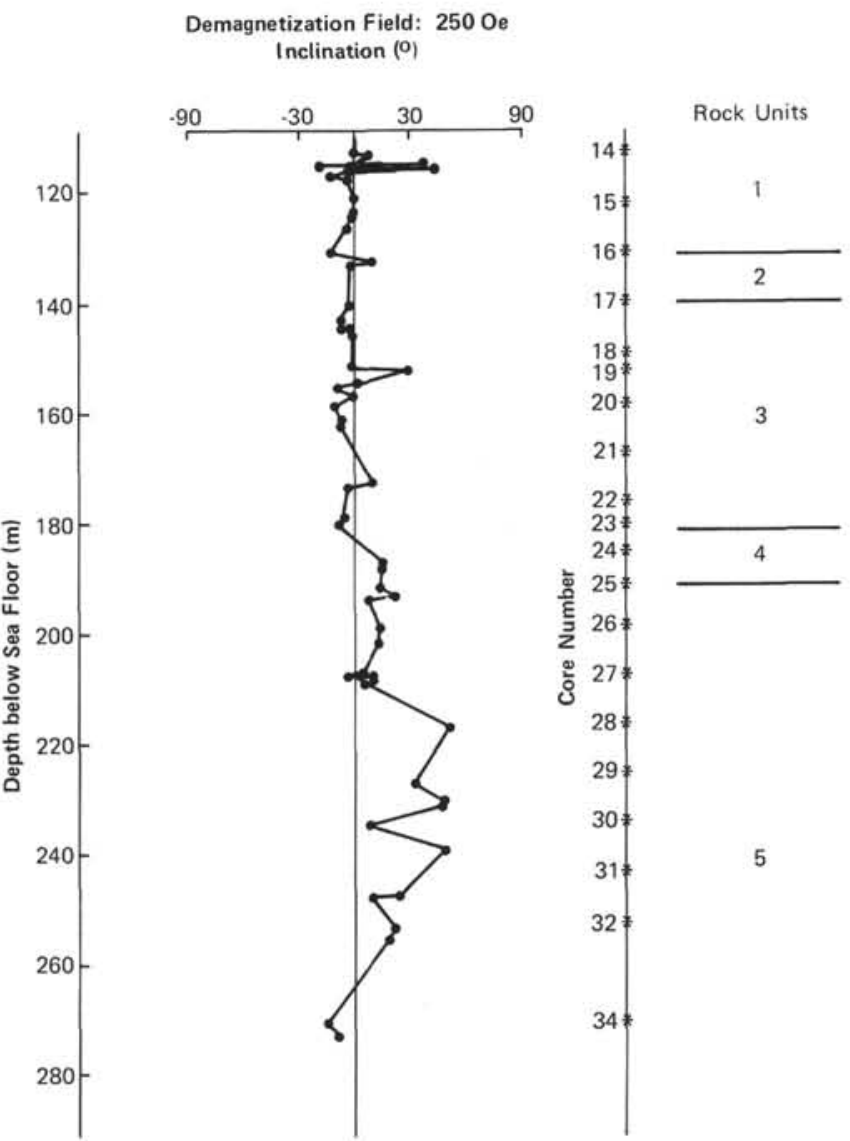

Figure 3. Stratigraphic plot of sample inclination after demagnetization to 250 Oe for samples from Hole 447A. (Sample directions displayed in this figure are summarized in Table 2.) 
Table 2. Stratigraphic summary of sample inclination and intensity, Holes 447A and 448A.

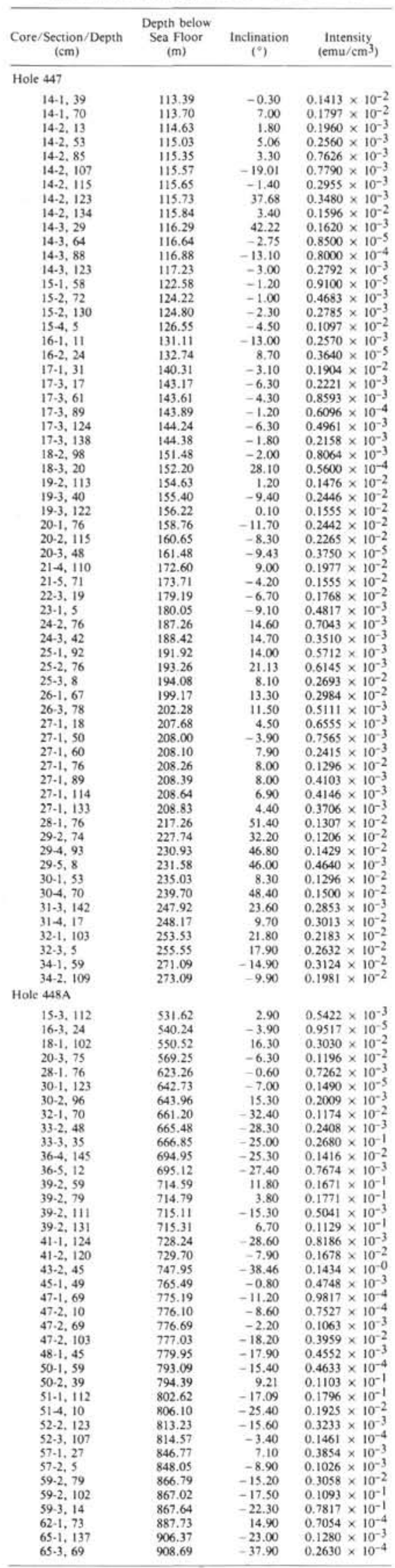

fied 51 petrographic units in Hole 448A; of these, 25 were sampled for paleomagnetic study, together with 1 additional unit in Hole 448. The number of samples per unit ranged from one to five, which was the sampling limit imposed on the shipboard scientific party.

A set of samples was selected from this hole as for the previous one, for detailed progressive demagnetization studies. This pilot set was demagnetized in multiple steps up to 1000 Oe alternating field. The remainder of the samples were demagnetized at $250 \mathrm{Oe}$. The results of these demagnetization studies are tabulated in Table 4. Stereonet projections of a few of the pilot study samples are shown in Figure 4. Most of the samples from this hole are stably magnetized and show very little change in direction upon demagnetization-e.g., 448A-30-1, $123,448 \mathrm{~A}-50-2,89,448 \mathrm{~A}-33-3,35,448 \mathrm{~A}-43-2,45$, 448A-51-1, 112, 448A-64-3, 145. Other samples from this hole, however, show very large directional changes on demagnetization, suggesting unstable magnetization-e.g., 448-61-3, 100, 448A-27-1, 37, 448A-50-2, 35 , and 448A-51-3, 47. In all, 16 samples showed very large directional changes and are interpreted as being unstably magnetized.

Plots of normalized intensity versus demagnetization field for some of the study samples are shown in Figure 5. Demagnetization curves are similar to those discussed from the previous site. As with Hole 447A, four types of demagnetization behavior were identified. The gradual decrease of intensity with demagnetization displayed by Samples 448A-33-3, 35, 448A-51-1, 112, and 448-61-3, 100 is characteristic of DSDP core material. Similarly, the demagnetization behavior displayed by Sample $448 \mathrm{~A}-30-1,123$ is commonly seen. The initial rise in intensity following the gradual decay reflects the removal of a secondary component of magnetization directed in the opposite sense to the primary, reversely magnetized component. The large drops in intensity observed in the basalts of Hole 447A are also observed in Samples 448A45-2, 5, 448A-51-2, 141, 448A-51-3, 47, and 448A-64-4, 16 , which suggests that most of the magnetization of these samples is an unstable (viscous?) component. Examination of the stereonet projections indicates that indeed these samples are very unstably magnetized. The last type of demagnetization behavior is displayed by Samples 448A-50-2, 89 and 448A-61-2, 136. These curves suggest that a low coercivity secondary component was removed and that a higher coercivity, more stable primary component remains. Of these samples, 448A-50-2, 89 is very stably magnetized and shows practically no change in sample direction on demagnetization. Sample 448A-61-2, 136, however, seems to be very unstably magnetized and shows large change in sample direction.

After the unstably magnetized samples were removed from the data set, a mean latitude was calculated for each of the petrographic units (Table 1). The paleolatitudes were found to range from $0.3^{\circ}$ to $16.3^{\circ}$ (excluding breccia units). When multiple samples could be compared, the polarity of all samples within a given petrographic unit was consistent in 7 cases out of 12 . By taking all the units together, two overall means were 
Table 3. Summary of NRM and demagnetized sample directions, Hole 447A.

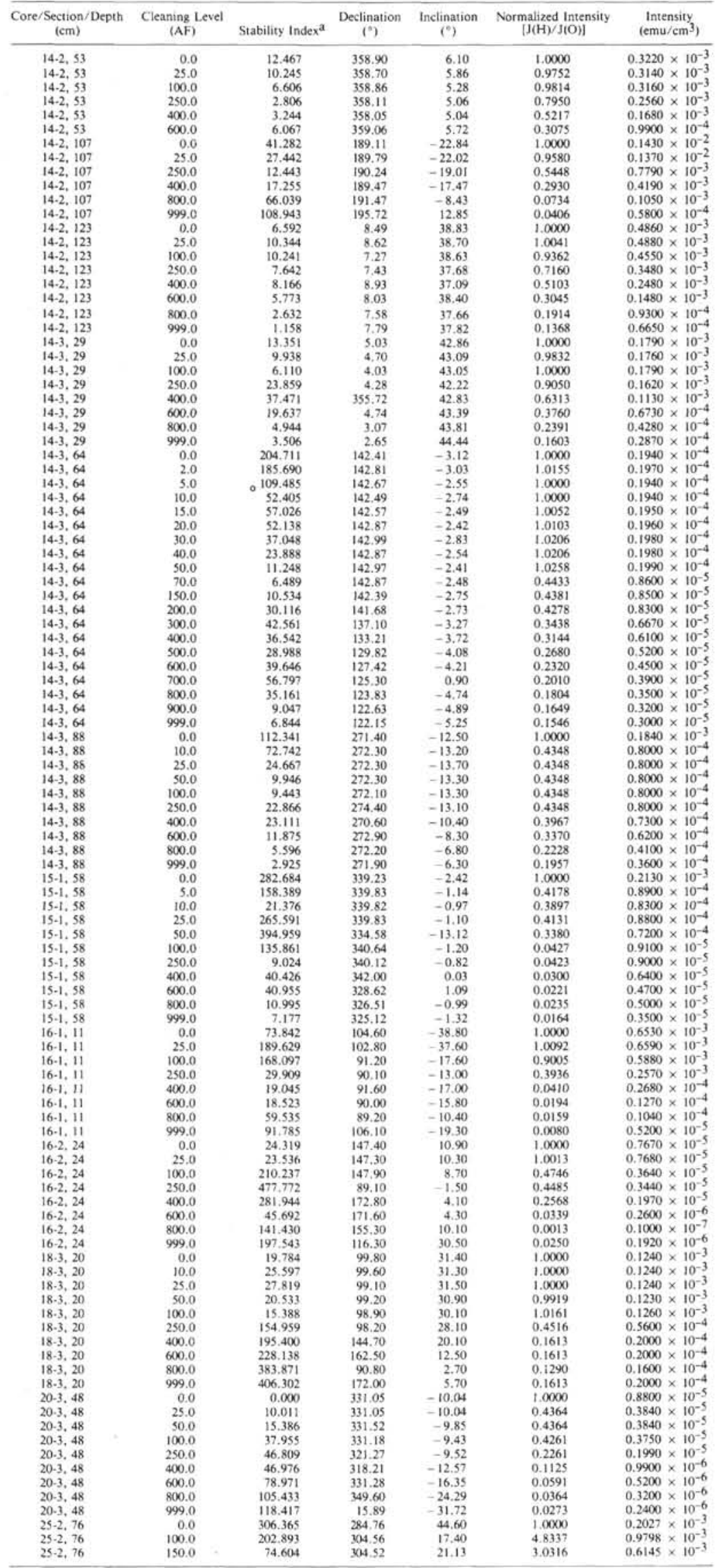

a Millidegrees per Oe. 
Table 4. Summary of NRM and demagnetized sample directions, Hole 448 and 448A.

\begin{tabular}{|c|c|c|c|}
\hline $\begin{array}{l}\text { Core/Section/Depth } \\
(\mathrm{cm})\end{array}$ & $\begin{array}{l}\text { Cleaning Level } \\
\text { (AF) }\end{array}$ & Stability Index $b$ & $\begin{array}{l}\text { Declination } \\
\left({ }^{\circ}\right)\end{array}$ \\
\hline $27-1,37$ & 0.0 & 279.095 & 237.80 \\
\hline $27-1,34$ & 25.0 & 248.647 & 228.20 \\
\hline $27-1,34$ & 100.0 & 245.041 & 248.60 \\
\hline $27-1,34$ & 250.0 & 158.311 & 199.70 \\
\hline $27-1,34$ & 400.0 & 75.434 & 194.80 \\
\hline $27-1,34$ & 600.0 & 167.811 & 175.70 \\
\hline $27-1,34$ & 800.0 & 209.168 & 132.20 \\
\hline $27-1,34$ & 999.0 & 182.310 & 94.90 \\
\hline $30-1,123$ & 0.0 & 19.995 & 0.00 \\
\hline $30-1,123$ & 25.0 & 20.942 & 0.50 \\
\hline $30-1,123$ & 100.0 & 26.502 & -1.10 \\
\hline $30-1,123$ & 250.0 & 67.995 & 2.00 \\
\hline $30-1,123$ & 400.0 & 76.776 & -7.50 \\
\hline $30-1,123$ & 600.0 & 232.748 & 0.80 \\
\hline $30-1,123$ & 800.0 & 121.772 & -45.70 \\
\hline $30-1,123$ & 999.0 & 10.600 & -47.80 \\
\hline $33-3,35$ & 0.0 & 61.273 & 12.45 \\
\hline $33-3,35$ & 5.0 & 37.010 & 12.65 \\
\hline $33-3,35$ & 10.0 & 16.909 & 12.72 \\
\hline $33-3,35$ & 20.0 & 10.508 & 12.71 \\
\hline $33-3,35$ & 40.0 & 72.421 & 12.71 \\
\hline $33-3,35$ & 80.0 & 121.735 & 8.70 \\
\hline $33-3,35$ & 120.0 & 89.861 & 6.93 \\
\hline $33-3,35$ & 160.0 & 46.025 & 4.23 \\
\hline $33-3,35$ & 200.0 & 7.627 & 4.62 \\
\hline $33-3,35$ & 250.0 & 10.744 & 4.67 \\
\hline $33-3,35$ & 300.0 & 23.934 & 4.81 \\
\hline $33-3,35$ & 350.0 & 22.916 & 3.15 \\
\hline $33-3,35$ & 400.0 & 14.513 & 3.58 \\
\hline $43-2,45$ & 0.0 & 0.000 & 56.92 \\
\hline $43-2,45$ & 5.0 & 0.000 & 56.92 \\
\hline $43-2,45$ & 10.0 & 6.594 & 56.92 \\
\hline $43-2,45$ & 20.0 & 8.743 & 56.76 \\
\hline $43-2,45$ & 40.0 & 3.223 & 56.80 \\
\hline $43-2,45$ & 80.0 & 2.266 & 56.76 \\
\hline $43-2,45$ & 120.0 & 2.931 & 56.72 \\
\hline $43 \cdot 2,45$ & 160.0 & 2.931 & 56.55 \\
\hline $43-2,45$ & 200.0 & 3.205 & 56.51 \\
\hline $43-2,45$ & 250.0 & 3.366 & 56.54 \\
\hline $43-2,45$ & 300.0 & 4.329 & 56.62 \\
\hline $43-2,45$ & 350.0 & 5.736 & 56.97 \\
\hline $43-2,45$ & 400.0 & 6.780 & 57.30 \\
\hline $43-2,45$ & 500.0 & 8.040 & 58.19 \\
\hline $43-2,112$ & 0.0 & 70.114 & 206.27 \\
\hline $45-2,5$ & 25.0 & 56.694 & 322.30 \\
\hline $45-2,5$ & 100.0 & 35.625 & 325.10 \\
\hline $45-2,5$ & 250.0 & 60.112 & 323.60 \\
\hline $45-2,5$ & 400.0 & 188.629 & 339.50 \\
\hline $45-2,5$ & 600.0 & 299.706 & 288.00 \\
\hline $45-2,5$ & 800.0 & 371.152 & 219.30 \\
\hline $45-2,5$ & 999.0 & 414.523 & 301.00 \\
\hline $50-2,35$ & 25.0 & 136.361 & 127.60 \\
\hline $50-2,35$ & 100.0 & 118.352 & 130.40 \\
\hline $50-2,35$ & 400.0 & 98.738 & 135.10 \\
\hline $50-2,35$ & 600.0 & 137.865 & 116.30 \\
\hline $50-2,35$ & 800.0 & 258.588 & 104.10 \\
\hline $50-2,35$ & 999.0 & 339.112 & 36.10 \\
\hline $50-2,89$ & 0.0 & 118.667 & 348.09 \\
\hline $50-2,89$ & 5.0 & 104.467 & 347.80 \\
\hline $50-2,89$ & 10.0 & 48.996 & 348.25 \\
\hline $50-2,89$ & 20.0 & 7.642 & 348.20 \\
\hline $50-2,89$ & 40.0 & 8.692 & 348.19 \\
\hline $50-2,89$ & 80.0 & 7.004 & 347.82 \\
\hline $50-2,89$ & 120.0 & 4.111 & 347.66 \\
\hline $50-2,89$ & 160.0 & 9.422 & 347.56 \\
\hline $50-2,89$ & 200.0 & 12.191 & 347.14 \\
\hline $50-2,89$ & 250.0 & 6.811 & 347.11 \\
\hline $50-2,89$ & 300.0 & 3.034 & 347.30 \\
\hline $50-2,89$ & 350.0 & 4.601 & 347.20 \\
\hline $50-2,89$ & 400.0 & 9.774 & 347.09 \\
\hline $50-2,89$ & 500.0 & 12.408 & 345.90 \\
\hline $51-1,112$ & 5.0 & 46.124 & 206.40 \\
\hline $51-1,112$ & 10.0 & 30.026 & 206.28 \\
\hline $51-1,112$ & 20.0 & 34.138 & 206.19 \\
\hline $51-1,112$ & 40.0 & 37.491 & 206.42 \\
\hline $51-1,112$ & 80.0 & 44.179 & 206.55 \\
\hline $51-1,112$ & 120.0 & 32.322 & 206.58 \\
\hline $51-1,112$ & 160.0 & 16.006 & 206.41 \\
\hline $51-1,112$ & 200.0 & 26.498 & 206.34 \\
\hline $51-1,112$ & 250.0 & 45.167 & 207.11 \\
\hline $51-1,112$ & 300.0 & 106.848 & 204.87 \\
\hline $51-1,112$ & 350.0 & 183.908 & 210.17 \\
\hline $51-1,112$ & 400.0 & 150.033 & 201.77 \\
\hline $51-1,112$ & 500.0 & 97.483 & 191.66 \\
\hline $51-2,134$ & 0.0 & 7.428 & 289.80 \\
\hline $51-2,134$ & 600.0 & 98.918 & 288.20 \\
\hline $51-2,134$ & 800.0 & 327.651 & 298.60 \\
\hline $51-2,134$ & 999.0 & 464.916 & 265.10 \\
\hline $51-2,141$ & 0.0 & 5070.616 & 295.60 \\
\hline $51-2,141$ & 10.0 & 2587.303 & 294.70 \\
\hline $51-2,141$ & 25.0 & 152.132 & 296.00 \\
\hline $51-2,141$ & 40.0 & 456.294 & 293.20 \\
\hline $51-2,141$ & 60.0 & 2084.341 & 278.10 \\
\hline $51-2,141$ & 80.0 & 2639.393 & 205.20 \\
\hline
\end{tabular}


Table 4. (Continued).

\begin{tabular}{|c|c|c|c|c|c|c|}
\hline $\begin{array}{c}\text { Core/Section/Depth } \\
(\mathrm{cm})\end{array}$ & $\begin{array}{l}\text { Cleaning Level } \\
\text { (AF) }\end{array}$ & Stability Index & $\begin{array}{l}\text { Declination } \\
\left({ }^{\circ}\right)\end{array}$ & $\begin{array}{c}\text { Inclination } \\
\left({ }^{\circ}\right)\end{array}$ & $\begin{array}{l}\text { Normalized Intensity } \\
{[\mathrm{J}(\mathrm{H}) / \mathrm{J}(\mathrm{O})]}\end{array}$ & $\begin{array}{l}\text { Intensity } \\
\left(\mathrm{emu} / \mathrm{cm}^{3}\right)\end{array}$ \\
\hline $51-2,141$ & 99.0 & 1822.347 & 238.70 & -45.90 & 0.0009 & $0.4470 \times 10^{-6}$ \\
\hline $51-3,47$ & 0.0 & 1902.915 & 47.90 & -6.70 & 1.0000 & $0.4320 \times 10^{-3}$ \\
\hline $51-3,47$ & 25.0 & 1297.791 & 0.00 & -6.70 & 0.1000 & $0.4320 \times 10^{-4}$ \\
\hline $51-3,47$ & 100.0 & 357.673 & 49.90 & -44.60 & 0.1016 & $0.4390 \times 10^{-4}$ \\
\hline $51-3,47$ & 250.0 & 55.752 & 51.00 & -41.30 & 0.0231 & $0.1000 \times 10^{-4}$ \\
\hline $51-3,47$ & 400.0 & 113.610 & 68.10 & -48.20 & 0.0435 & $0.1880 \times 10^{-4}$ \\
\hline $51-3,47$ & 600.0 & 143.802 & 93.40 & -31.00 & 0.0280 & $0.1210 \times 10^{-4}$ \\
\hline $51-3,47$ & 800.0 & 150.943 & 127.30 & -52.60 & 0.0604 & $0.2610 \times 10^{-4}$ \\
\hline $51-3,47$ & 999.0 & 152.678 & 130.90 & -22.40 & 0.0161 & $0.6960 \times 10^{-5}$ \\
\hline $61-2,136$ & 0.0 & 60.078 & 275.10 & -52.90 & 1.0000 & $0.1100 \times 10^{-3}$ \\
\hline $61-2,136$ & 25.0 & 286.490 & 277.50 & -52.50 & 1.0091 & $0.1110 \times 10^{-3}$ \\
\hline $61-2,136$ & 100.0 & 556.221 & 261.60 & -17.20 & 0.9273 & $0.1020 \times 10^{-3}$ \\
\hline $61-2,136$ & 250.0 & 327.082 & 351.70 & -7.00 & 0.7636 & $0.8400 \times 10^{-4}$ \\
\hline $61-2,136$ & 400.0 & 102.663 & 359.30 & -4.10 & 0.0582 & $0.6400 \times 10^{-5}$ \\
\hline $61-2,136$ & 600.0 & 115.102 & 329.20 & -1.10 & 0.0873 & $0.9600 \times 10^{-5}$ \\
\hline $61 \cdot 2,136$ & 800.0 & 147.594 & 313,40 & -1.10 & 0.0658 & $0.7240 \times 10^{-5}$ \\
\hline $61-2,136$ & 999.0 & 216.203 & 347,90 & 29.80 & 0.0234 & $0.2570 \times 10^{-5}$ \\
\hline $64-3,145$ & 0.0 & 135.706 & 2.45 & -29.61 & 1.0000 & $0.1081 \times 10^{+0}$ \\
\hline $64-3,145$ & 5.0 & 108.793 & 1.72 & -29.85 & 1.0000 & $0.1081 \times 10^{+0}$ \\
\hline $64-3,145$ & 10.0 & 48.273 & 1.69 & -30.26 & 0.9954 & $0.1076 \times 10^{+0}$ \\
\hline $64-3,145$ & 20.0 & 9.914 & 1.82 & -30.35 & 0.9935 & $0.1074 \times 10^{+0}$ \\
\hline $64-3,145$ & 40.0 & 4.520 & 1.77 & -30.45 & 0.9898 & $0.1070 \times 10+0$ \\
\hline $64-3,145$ & 80.0 & 3.613 & 1.89 & -30.55 & 0.9889 & $0.1069 \times 10^{+0}$ \\
\hline $64-3,145$ & 120.0 & 3.611 & 2.00 & -30.44 & 0.9852 & $0.1065 \times 10^{+0}$ \\
\hline $64-3,145$ & 160.0 & 3.050 & 2.13 & -30.53 & 0.9852 & $0.1065 \times 10^{+0}$ \\
\hline $64-3,145$ & 200.0 & 6.417 & 2.12 & -30.43 & 0.9806 & $0.1060 \times 10^{+0}$ \\
\hline $64-3,145$ & 500.0 & 10.324 & 358.55 & -30.17 & 0.0800 & $0.8643 \times 10^{-2}$ \\
\hline $64-4,16$ & 0.0 & 147.339 & 228.80 & -14.90 & 1.0000 & $0.4800 \times 10^{-3}$ \\
\hline $64-4,16$ & 25.0 & 79.182 & 231.50 & -17.50 & 0.0208 & $0.1000 \times 10^{-4}$ \\
\hline $64-4,16$ & 100.0 & 12.211 & 232.20 & -16.90 & 0.0069 & $0.3300 \times 10^{-5}$ \\
\hline $64-4,16$ & 250.0 & 27.454 & 230.40 & -16.20 & 0.0162 & $0.7800 \times 10^{-5}$ \\
\hline $64-4,16$ & 400.0 & 52.034 & 223.90 & -17.70 & 0.0050 & $0.2400 \times 10^{-5}$ \\
\hline $64-4,16$ & 600.0 & 146.402 & 227.10 & -5.80 & 0.0108 & $0.5200 \times 10^{-5}$ \\
\hline $64-4,16$ & 800.0 & 244.662 & 180.90 & -2.80 & 0.0002 & $0.1140 \times 10^{-6}$ \\
\hline $64-4,16$ & 999.0 & 258.112 & 196.60 & -53.30 & 0.0014 & $0.6520 \times 10^{-6}$ \\
\hline $61-3,100^{a}$ & 0.0 & 97.303 & 166.21 & 24.39 & 1.0000 & $0.1222 \times 10^{-2}$ \\
\hline $61-3,100^{\mathrm{a}}$ & 25.0 & 110.235 & 167.85 & 26.31 & 0.9910 & $0.1211 \times 10^{-2}$ \\
\hline $61-3,100^{\mathrm{a}}$ & 50.0 & 152.595 & 164.40 & 26.28 & 0.9386 & $0.1147 \times 10^{-2}$ \\
\hline $61-3,100^{\mathrm{a}}$ & 100.0 & 126.309 & 154.25 & 26.99 & 0.7797 & $0.9528 \times 10^{-3}$ \\
\hline $61-3,100^{\mathrm{a}}$ & 150.0 & 116.534 & 157.17 & 24.62 & 0.5919 & $0.7233 \times 10^{-3}$ \\
\hline $61-3,100^{\mathrm{a}}$ & 200.0 & 103.789 & 149.23 & 21.33 & 0.4718 & $0.5766 \times 10^{-3}$ \\
\hline $61-3,100^{\mathrm{a}}$ & 300.0 & 45.682 & 145.03 & 23.80 & 0.3329 & $0.4068 \times 10^{-3}$ \\
\hline
\end{tabular}

calculated. From the absolute values of the sample inclinations, the mean paleolatitude is $7.8^{\circ}\left(\mathrm{SD}=10.0^{\circ}\right)$. Using both polarities (positive and negative inclination values), the mean paleolatitude is $5.7^{\circ}(\mathrm{SD}=14.5)$. Mean paleolatitudes have also been calculated on the basis of petrographic characteristics. In this case, the flows, breccia units, and tuffs have mean latitudes similar to the overall site mean $\left(6.6^{\circ}, 7.3^{\circ}\right.$, and $7.7^{\circ}$, respectively). The pillow basalts display lower (mean $=$ $4.4^{\circ}$ ) and the sills higher $\left(\right.$ mean $=8.3^{\circ}$ ) paleolatitudes. The phyric basalts have a mean paleolatitude of $6.5^{\circ}$, similar to the site mean, whereas the aphyric group is much higher, $11.0^{\circ}$. Likewise, the nonvesicular basalts are characterized by a mean similar to the site mean $\left(6.3^{\circ}\right)$, and the vesicular basalts have a much higher paleolatitude $\left(10.2^{\circ}\right)$. These paleolatitudes are quite consistent, suggesting that the paleoinclinations were not significantly biased by the rock type.

The individual sample inclinations have been plotted stratigraphically in Figure 6. Excluding the occasional single sample with opposite polarity (which we believe reflects undetected sample inversions), all of the sequence from Hole 448A except for Core 36 is characterized by negative inclinations. The samples from Core 36 are from a breccia unit and would not be expected to give reliable polarity results. The samples from Hole 448 come from five different units; the first two are breccia units, the next two are flow units, and the final sample represents a pillow basalt unit. Only one sample was taken from each unit, and both positive and negative inclinations are present in these units.
The distribution of sample intensities for Hole 448A is shown in Figure 7. The majority of the samples fall in the range of $1.0 \times 10^{-4}, 1.0 \times 10^{-2} \mathrm{emu} / \mathrm{cm}^{3}$. However, a large number of samples are much more strongly magnetized and fall in the range of $1.0 \times 10^{-1}$ to 1.0 $\mathrm{emu} / \mathrm{cm}^{3}$. Because these samples are unusually strongly magnetized relative to other DSDP samples, we resampled the intervals of the core from which they were taken. On examination, we found that these intervals were extemely altered segments of the core near intrusions. Magnetic property studies and thin section studies are currently underway and will be the subject of a later publication.

Curie temperature experiments (using samples in vacuum capsules) have been completed on several of the basalts from Hole 448A that display the anomalous intensities. Examples of the results are seen in Figure 8. The Curie temperature studies for Sample 448A-33-3, 35 (see Intensity, Table 4) indicate the presence of two magnetic phases with Curie points of approximately $330^{\circ}$ and $475^{\circ}$. The experimental curve for this sample is nonreversible. Sample 448A-43-2, 45, however, shows a single Curie temperature at roughly $350^{\circ} \mathrm{C}$. As with the previous sample, the curve is irreversible. Sample 448A-64-3, 145 shows a similar Curie temperature of approximately $350^{\circ} \mathrm{C}$, but in contrast this thermomagnetic curve is almost reversible.

\section{SUMMARY}

Paleomagnetic studies of basement rocks from Sites 447 and 448 indicate that both of these sites were situ- 

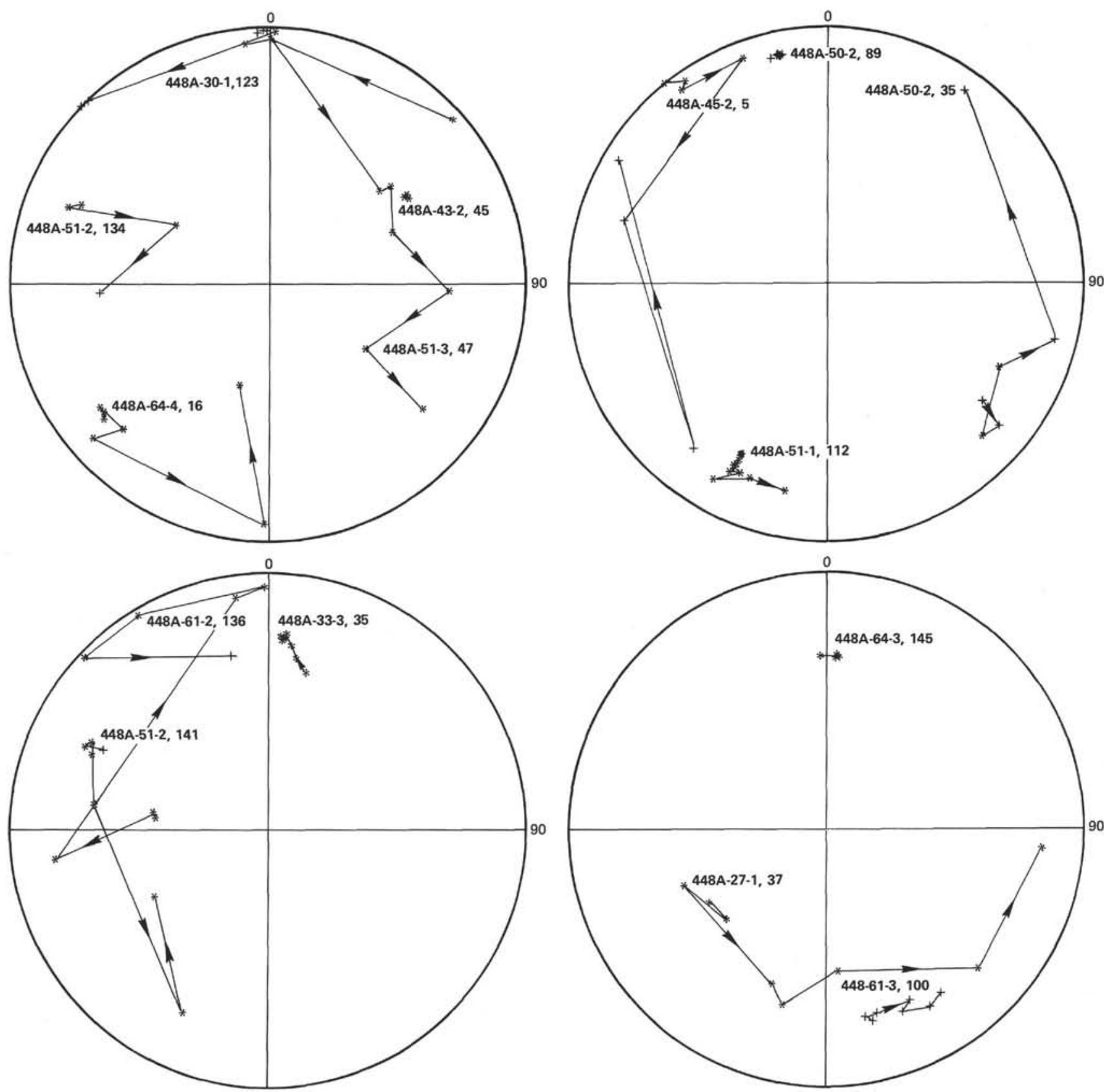

Figure 4. Stereonet projections of progressive changes in magnetic directions of demagnetization for samples from Holes 448 and $448 \mathrm{~A}$. (Arrows indicate direction with change upon progressive demagnetization, stars $=$ negative inclination, and crosses $=$ positive inclination.)

ated close to the equator at the time the basement rocks were formed. The mean paleolatitude for Site 447 is 6.0 $(\mathrm{SD}=13.1)$, and the mean paleolatitude for Site 448 is $7.8^{\circ}(\mathrm{SD}=10.0)$. These results are similar to the paleolatitudes calculated from studies of sediments at these two sites. The mean paleolatitude of sediments at Site 447 is 10.2 , and the mean paleolatitude for sediments at Site 448 is $4.7^{\circ}$. The hemisphere in which these sediments were deposited is indeterminate, however. These sites are presently at roughly $18^{\circ} \mathrm{N}$ latitude. The differences between the present site latitudes and the paleolatitudes based the paleomagnetic studies of the basalts suggest that significant northward plate motion has occurred. For Site 447, the paleolatitudes are consis- tent with between $12^{\circ}$ and $24^{\circ}$ of plate motion, depending on whether the basalts were formed north or south of the equator. The mean paleolatitudes calculated for Site 448 are consistent with $10^{\circ}$ to $26^{\circ}$ of northward motion.

Because these sites are so close to the magnetic equator and because we cannot ascertain on which side of the equator the rocks formed, it is impossible to assign polarities to the samples. Both positive and negative inclinations are present in Hole 447A and they occur in consistent stratigraphic groups. In Hole $448 \mathrm{~A}$ almost the entire sequence is magnetized negatively. The exception occurs in a breccia sequence, which might not be expected to yield reliable inclinations or polarity 

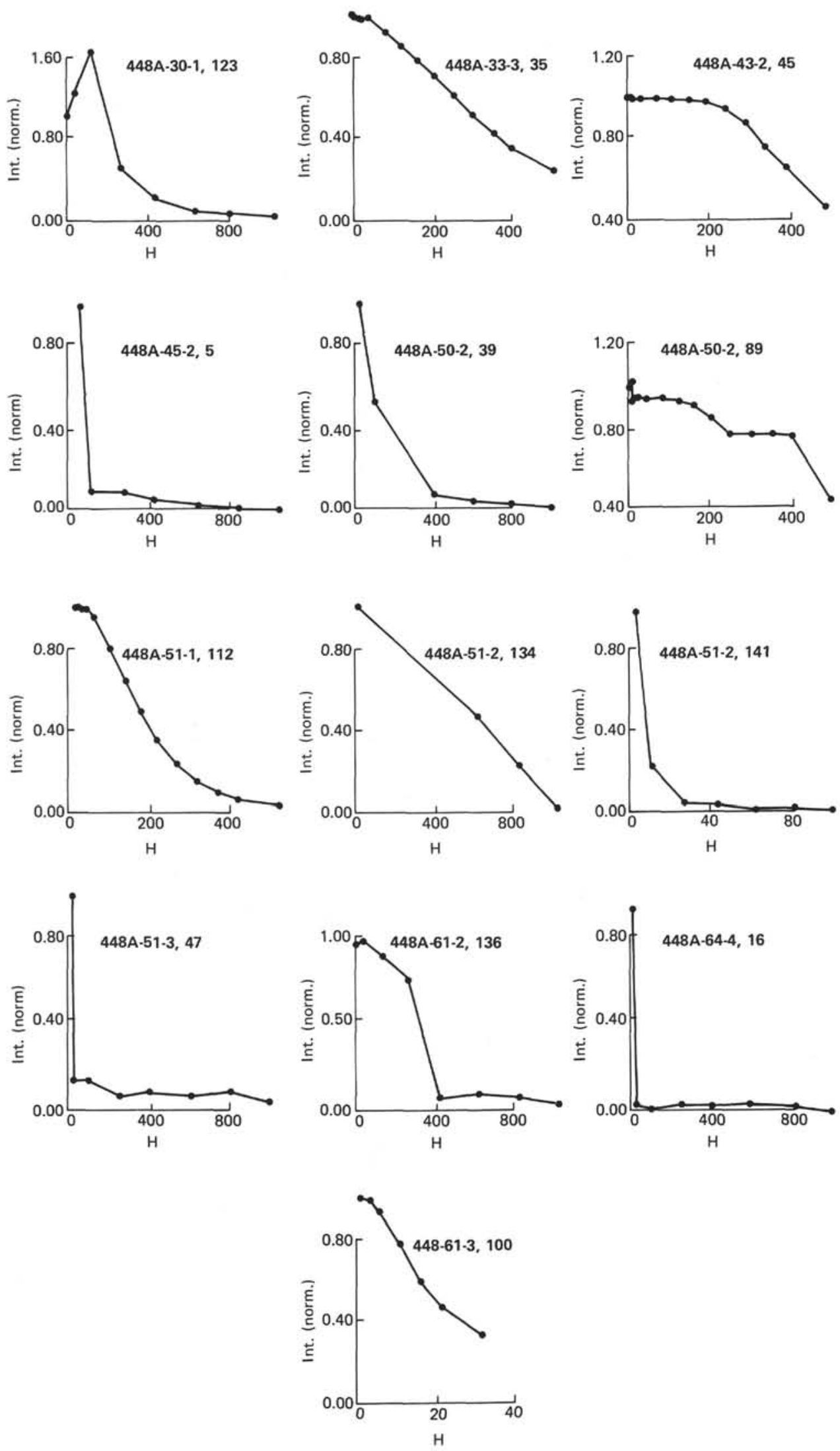

Figure 5. Plots of normalized intensity versus alternating current demagnetization field (Oe) for samples from Holes 448 and $448 \mathrm{~A}$. (The last sample is from Hole 448.) 


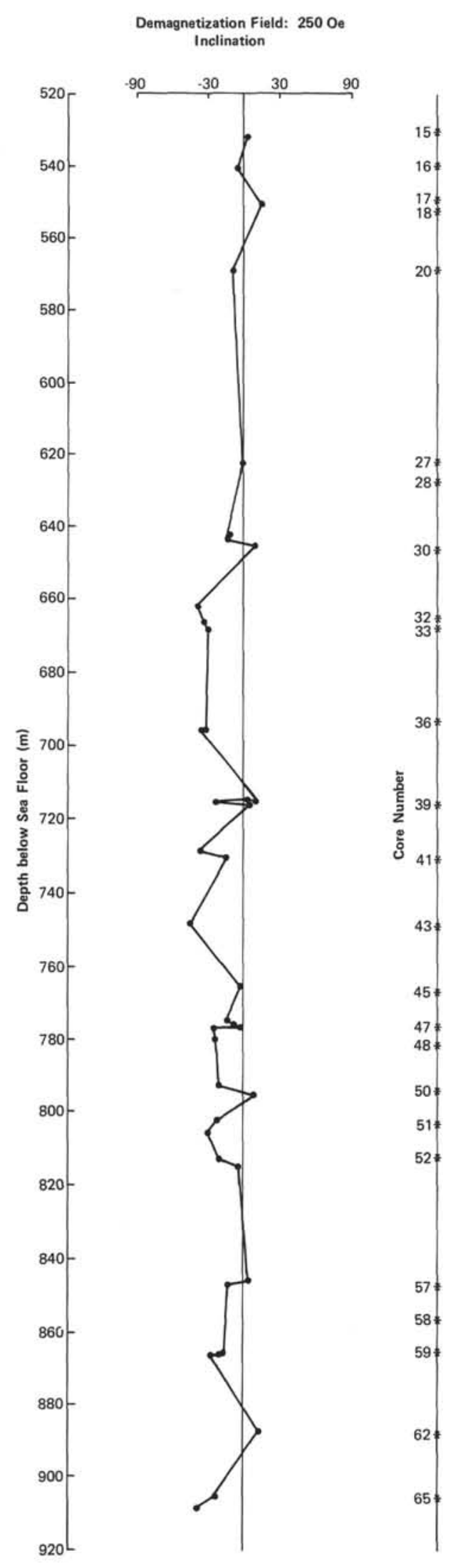

Figure 6. Stratigraphic plot of magnetic inclinations after demagnetization to 250 Oe for samples from Hole $448 \mathrm{~A}$. (Sample directions are summarized in Table 2.)
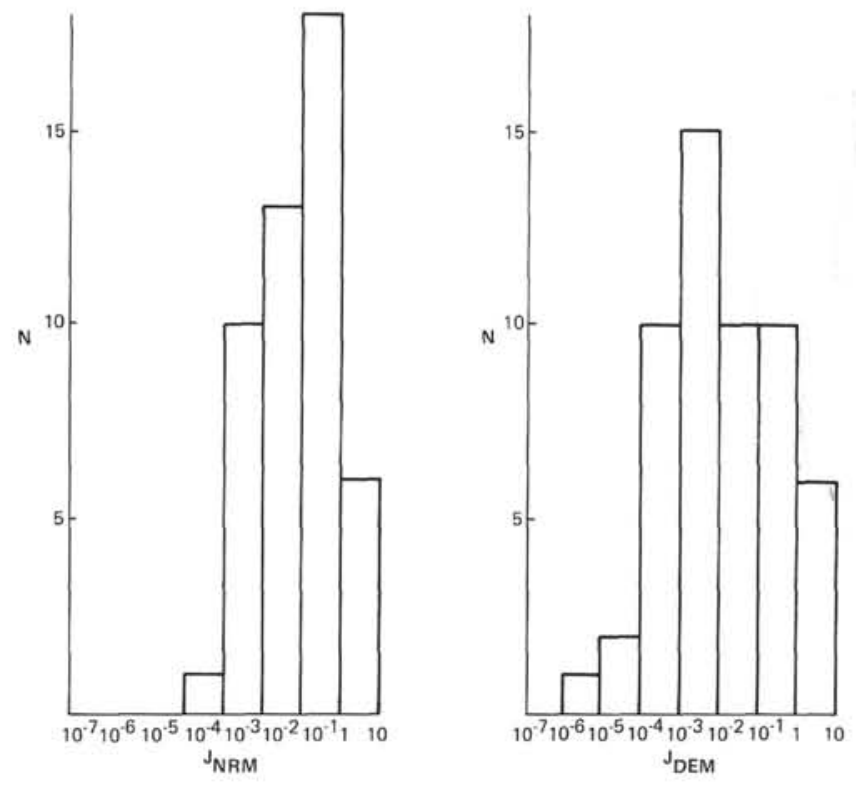

Figure 7. Histogram of sample intensities for Hole 448A. (Magnetic moments are measured in $\mathrm{emu} / \mathrm{cm}^{3}$.)

determinations. Other breccia units sampled, however, do appear to yield a consistent polarity and paleoinclination. Shipboard discussions by petrologists suggest that some of the breccia units have undergone thermal alteration. This suggestion would help to explain the conformability of most of the breccia paleomagnetic directions.

An additional point to be raised is that secular motion of the earth's field may play an important part in the magnetization of these samples. Numerous petrographic units have been sampled at Sites 447 and 448, but we have little idea of the age of the units or their duration in time. If these units represent sufficiently long periods of time (several thousand years), then the scatter of direction caused by secular variation of the earth's magnetic field should be averaged out. Because this seems unlikely, it is possible that the magnetic directions recorded in these samples do not accurately reflect the earth's dipolar field but record instead the secular variation of the field. Because we cannot rule out this possibility, we have an additional reason not to assign polarity in these rock units. (Likewise, the paleolatitude estimates should be considered only approximate ones.) When plotted stratigraphically, particularly in Hole $448 \mathrm{~A}$, the inclinations are reasonably consistent. This observation in itself suggests that these samples do record dipolar field directions.

Numerous samples from Hole 448A display very high magnetic moments. Thermomagnetic studies have been conducted on several of them. Some of the samples display Curie temperatures of $330^{\circ}$ to $475^{\circ}$, indicative of the presence of titanomagnetite. Optical studies, particularly of Sample 448A-33-3, 35, are required in order to confirm the identity of the magnetic minerals. The large magnetic moments found in these samples are unusual, since normal alteration (oxidation) of the ocean crust acts to reduce the magnetic moment (Marshall 

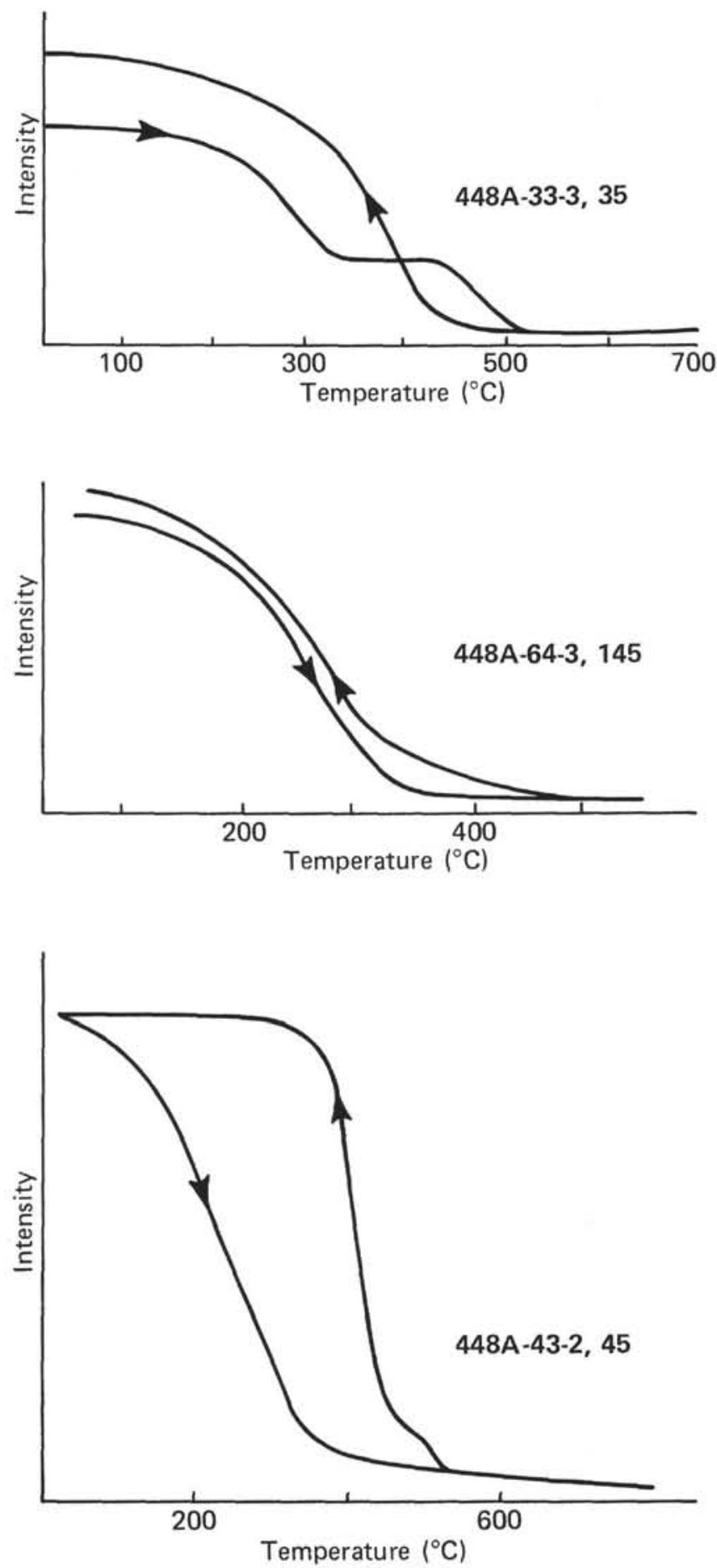

Figure 8. Thermomagnetic curves from samples from Hole 448A.

and Cox, 1971, 1972). Physical observation of the samples suggests that in this hole the alteration (perhaps deuteric?) has resulted in the unusually high magnetic moments.

\section{ACKNOWLEDGMENTS}

We thank V. Hsu for his help with computer programs and with the measurement of these samples. This manuscript was reviewed by
C. E. Helsley and S. Hammond and is Hawaii Institute of Geophysics Contribution No. 1058

\section{REFERENCES}

Marshall, M., and Cox, A., 1971. Effect of oxidation on the natural remanent magnetization of titanomagnetite in submarine basalt Nature, 230:28-31.

1972. Magnetic changes in pillow basalt due to sea floor weathering. Geophys. Res., 72:6459-6469. 